\title{
Low Knowledge and Negative Perception about the Risks of Breast Cancer among Female High School Students
}

\author{
Sri Yusnita Irda Sari, ${ }^{1}$ Dini Desmona, ${ }^{2}$ Teguh Marfen Djajakusumah ${ }^{3}$ \\ ${ }^{1}$ Department of Public Health Faculty of Medicine Universitas Padjadjaran, Indonesia, \\ ${ }^{2}$ Faculty of Medicine Universitas Padjadjaran, Indonesia, ${ }^{3}$ Department of Surgery Faculty of \\ Medicine Universitas Padjadjaran/Dr. Hasan Sadikin General Hospital Bandung, Indonesia
}

\section{Abstract}

Background: Breast cancer is one of the leading causes of death among women. The potential risk factor is older age, however, the prevalence at a young age is recently increased. Unfortunately, young women show a poor level of knowledge about breast cancer. This study aimed to explore the knowledge and perception among female high school students about the risks of breast cancer.

Methods: This cross-sectional study was conducted from October to November 2013 in Jatinangor. One hundred and eighteen (n118) female students from three senior high schools were included in this study. Data on mother's educational status, family income, family history of breast cancer and number of a family members living in the same house was collected. Knowledge and perception toward risks of breast cancer were assessed using a validated questionnaire.

Results: Most of the students (69.5\%) had a poor level of knowledge about breast cancer. Furthermore, they also had a negative perception (43.2\%) toward breast cancer's risks. Factor influencing their perception was family income $(\mathrm{p}=0.012)$ and knowledge about breast cancer $(\mathrm{p}=0.008)$.

Conclusions: Young female high school students have low knowledge and negative perception about the risks of breast cancer. It is recommended that education about breast care and breast cancer should be given to high school female students to improve their knowledge and to early detect abnormality in their breast.

Keywords: Breast cancer, knowledge, perception, risk

\section{Introduction}

Breast cancer is the most common cancer affecting women from all the races in the world, both in the developed and less developed countries.1,2 Breast cancer is also the most frequently diagnosed cancer and the leading cause of death among women in a developing country. The prevalence of breast cancer is $23 \%$ of the total cancer cases and $14 \%$ of cancer deaths, ${ }^{3}$ which is higher in developing countries than developed countries, as most of patients seek medical assistance in the latestage. ${ }^{4}$ Early detection of breast cancer such as mammography, ultrasonography (USG), clinical breast examination and self-breast examination might help detect breast cancer at early stage and can reduce the mortality rate., ${ }^{4,5}$

Although breast cancer is more common among women above 35 years old, however, some cases can also be found at a younger age. Moreover, breast canceris more aggresive in younger patients, therefore, all women especially at younger age need to understand the importance of early detection of breast cancer. $^{6}$ However, most the young women have shown a deficit of knowledge and lack of awareness about breast cancer. ${ }^{7-13}$ Age, level of education, employment status and family member living in the same house may affect their knowledge about breast cancer.,14 In Australia, information barrier is one of the most important causes and some have

Correspondence: Sri Yusnita, Department of Public Health Faculty of Medicine Faculty of Medicine Universitas Padjadjaran, Jalan Prof. Eyckman No. 38, Bandung, Indonesia Email: italatif@yahoo.com 
incorrect perception about breast cancer, assuming that breast cancer would not happen to them and only for older women..$^{15}$ This study was conducted to explore the knowledge and perception about the risks of breast cancer among students from high schools in Jatinangor.

\section{Methods}

A cross-sectional study was conducted in three senior high schools in Jatinangor from October to November in 2013. After calculation, the minimum effective sample size was 110 respondents. The first stage, three of ten senior high schools in the subdistrict of Jatinangorwere randomly chosen. In the the second stage, the classes were randomized picked up, and in total, 40 students from each school were randomly chosen as participants. The inclusion criteria were second-grade female students aged 14-19 years old who consented to participate in this study. The exclusion criteria were incomplete data and students who were resigned as the study proceeded.

The instrument of the studywas a selfadministered questionnaire about the knowledge and perception of the risks of breast cancer. The questionnaire had been validated beforehand in 21 female students from a high school other than the current study in Jatinangor. The questionnaire was developed based on the theory of the risk factors in breast cancer. ${ }^{16}$ Cronbach alpha value was 0.686 for the questionnaire of knowledge and 0.550 forquestionnaire of perception.

After signing an informed consent form, respondents had answered the first part of a questionnaire about the characteristic of the respondents, consisting of the educational level of their mother, family income, family history of breast cancer and the number of their family members that lives in the same house. Next part, respondents had answered

Table 1 The Characteristics of Female Senior High School Students in Jatinangor Recruited in the Study.

\begin{tabular}{lcc}
\hline \multicolumn{1}{c}{ Variables } & Frequencies (n=118) & Percentage (\%) \\
\hline Age (years old) & 11 & 9.0 \\
15 & 81 & 66.4 \\
16 & 26 & 22.0 \\
17 & & \\
The educational level of the mother & 34 & 28.8 \\
$\quad$ Elementary graduated & 18 & 15.3 \\
Junior high school graduated & 34 & 28.8 \\
Senior high school graduated & 32 & 27.1 \\
Diploma/bachelor & & \\
Family Income & 23 & 19.5 \\
< Rp1.050.000 & 41 & 34.7 \\
Rp1.050.000 - 2.000.000 & 25 & 21.2 \\
Rp2.000.000 - 6.000.000 & 29 & 24.6 \\
$>$ Rp6.000.000 & & \\
Family history of breast cancer & 104 & 88.1 \\
No family history & 14 & 11.9 \\
Yes, there is a family history & & \\
Number of a family member that lives in the same & & 61.9 \\
house & 73 & 38.1 \\
$\quad$ 5 & 45 & \\
> 5 & & \\
\hline
\end{tabular}


Table 2 Knowledge and Perception Toward the Risks of Breast Cancer among Female Senior High School Students in Jatinangor

\begin{tabular}{|c|c|c|}
\hline Variables & Frequencies (n) & Percentage (\%) \\
\hline \multicolumn{3}{|l|}{ Level of knowledge } \\
\hline Poor & 82 & 69.5 \\
\hline Moderate & 36 & 30.5 \\
\hline Good & - & - \\
\hline \multicolumn{3}{|l|}{ Perception } \\
\hline Positive & 67 & 56.8 \\
\hline Negative & 51 & 43.2 \\
\hline
\end{tabular}

a 20-questions questionnaire about their knowledge of breast cancer risks. For the last part, respondents hadanswered a 12-questions questionnaire about their perception of breast cancer risks. For each statement on the knowledge, a correct answer was scored with a value of one, while an incorrect answer or did not know was scored at zero; the maximum score in the knowledge questionnaire was 20 , and the minimum was zero. For statements on perception, if it was a positive statement, it was scored four for strongly agree, three for agree, two for disagree, and one for strongly disagree. For negative statements on perception, it was

Table 3 Items Measuring the PerceptionToward the risks of Breast Cancer

\begin{tabular}{lcccc}
\hline \multicolumn{1}{c}{ Variables } & $\begin{array}{c}\text { Strongly } \\
\text { agree } \\
\text { (\%) }\end{array}$ & $\begin{array}{c}\text { Agree } \\
\text { (\%) }\end{array}$ & $\begin{array}{c}\text { Disagree } \\
\text { (\%) }\end{array}$ & $\begin{array}{c}\text { Strongly } \\
\text { Disagree } \\
\text { (\%) }\end{array}$ \\
\hline $\begin{array}{l}\text { Breast cancer will not happen to young women } \\
\begin{array}{l}\text { The mother who has breast cancer will not increase the } \\
\text { risk of her daughter of getting breast cancer }\end{array}\end{array}$ & 6.8 & 24.6 & 59.3 & 9.3 \\
$\begin{array}{l}\text { Women who reach menarche on age younger than 12 } \\
\text { years old, has an increased risk of getting breast cancer }\end{array}$ & 3.4 & 11.9 & 73.7 & 11.0 \\
$\begin{array}{l}\text { Women who experience a first full-term pregnancy at } \\
\text { ages older than 35 years old will increase her risk of } \\
\text { getting breast cancer }\end{array}$ & 0.8 & 31.4 & 58.5 & 9.3 \\
$\begin{array}{l}\text { Alcohol makes women immune to breast cancer } \\
\begin{array}{l}\text { Breastfeeding will protect women from getting breast } \\
\text { cancer }\end{array}\end{array}$ & 6.8 & 22.9 & 29.7 & 40.7 \\
$\begin{array}{l}\text { Using oral or hormonal contraceptives containing } \\
\text { estrogen will increase the risk of getting breast cancer }\end{array}$ & 5.1 & 47.5 & 11.9 & 0.0 \\
$\begin{array}{l}\text { Women should take seriously for any problem } \\
\text { concerning their breast condition }\end{array}$ & 64.4 & 33.1 & 1.7 & 0.7 \\
$\begin{array}{l}\text { Being a woman will increase the risk of getting breast } \\
\text { cancer }\end{array}$ & 32.2 & 47.5 & 17.8 & 2.5 \\
$\begin{array}{l}\text { Indonesian women have risk of getting breast cancer as } \\
\text { this country has a high incidence of that cancer }\end{array}$ & 5.1 & 34.7 & 38.1 & 22.0 \\
$\begin{array}{l}\text { The polluted environment will not affect women on } \\
\text { getting breast cancer }\end{array}$ & 7.6 & 26.3 & 53.4 & 12.7 \\
$\begin{array}{l}\text { Exposure to radiation will increase the risk of getting } \\
\text { breast cancer }\end{array}$ & 21.2 & 50.0 & 23.7 & 5.1 \\
\hline
\end{tabular}


Table 4 The Perception Toward the Risks of Breast Cancer among Female Senior High School Students in Jatinangor Based on Their Characteristics

\begin{tabular}{|c|c|c|c|c|}
\hline \multirow{2}{*}{ Characteristics } & \multicolumn{2}{|c|}{ Perception } & \multirow{2}{*}{$\mathbf{R}$} & \multirow{2}{*}{$\mathbf{P}$} \\
\hline & Positive (+) & Negative(-) & & \\
\hline \multicolumn{5}{|l|}{ The educational level of a mother } \\
\hline Elementary graduated & 16 & 18 & \multirow{4}{*}{0.141} & \multirow{4}{*}{0.127} \\
\hline Junior high school graduated & 10 & 8 & & \\
\hline Senior high school graduated & 20 & 14 & & \\
\hline Diploma/bachelor & 21 & 11 & & \\
\hline \multicolumn{5}{|l|}{ Family income } \\
\hline$<\mathrm{Rp} 1,050,000$ & 9 & 14 & \multirow{4}{*}{0.230} & \multirow{4}{*}{$0.012^{*}$} \\
\hline Rp1,050,000 - 2,000,000 & 20 & 21 & & \\
\hline $\mathrm{Rp} 2,000,000-6,000,000$ & 19 & 6 & & \\
\hline$>\operatorname{Rp} 6,000,000$ & 19 & 10 & & \\
\hline \multicolumn{5}{|l|}{ Family history of breast cancer } \\
\hline Yes, there is a family history & 8 & 6 & \multirow{2}{*}{-0.003} & \multirow{2}{*}{0.977} \\
\hline No family history & 59 & 45 & & \\
\hline \multicolumn{5}{|l|}{ Number of a family member } \\
\hline$\leq 5$ & 39 & 34 & \multirow{2}{*}{0.086} & \multirow{2}{*}{0.353} \\
\hline$>5$ & 28 & 17 & & \\
\hline
\end{tabular}

scored in a reverse way. The maximum score for the perception questionnaire was 48 and the minimum was 12 . The level of knowledge was divided into three groups, consisting of poor, moderate and good knowledge; which was $<50 \%, 50-75 \%$, and $>75 \%$, respectively. The perception of the respondents was grouped into positive perceptions and negative perceptions. Positive perception referred to subject perceived things according to the right knowledge and acceptable reason. The negative perception was arisen due to a lack of knowledge and experience of the subject to the object perceived. The basis for this grouping was the median from all the respondent's score of questionnaire perception when the distribution was not normal. This study was approved by the Health Research Ethics Committee, Faculty of Medicine Universitas Padjadjaran.

All data were analyzed using the Statistical Product and Service Solutions (SPSS) version 15.0. After a process of scoring, the data distribution of respondents' characteristics, knowledge and perception were analyzed using the Kolmogorov-Smirnov method. To assess the relationship between the respondent's characteristics and knowledge with perception on breast cancer risk, the spearman correlation test had been used because the data was not normally distributed. The level of statistical significance was set at $\mathrm{p}<0.05$.

\section{Results}

Out of 73 students, mostly were flatfoot (n 40; In total, 120 students were participated, of whom 2 were excluded due to incomplete answers. Of these 118 students, the mean age was 16.13 years old (15-17 years old). The education of their mothers was at a good level (55.9\%), consisting of senior high school and diploma/bachelor graduated. The family income was higher than the minimum regional payment for Sumedang regency which was Rp1,381,700,00 in 2013 (Table 1).

Most of the students had a poor level of knowledge toward the risks of breast cancer (Table 2), however, most of the students showed positive perception toward breast cancer's risk, even though there was no significant difference in percentage with respondents who had a negative perception. The overall mean total score of the knowledge 
Table 5 The Relationship between the Level of Knowledge and Perception Toward the Risks of Breast Cancer among Female Senior High School Students in Jatinangor

\begin{tabular}{|c|c|c|c|c|}
\hline \multirow{2}{*}{ knowledge } & \multicolumn{2}{|c|}{ Perception } & \multirow{2}{*}{$\mathbf{R}$} & \multirow{2}{*}{$\mathbf{P}$} \\
\hline & Positive (+) & Negative(-) & & \\
\hline Good & - & - & & \\
\hline Moderate & 27 & 9 & 0.244 & 0.008 \\
\hline Poor & 40 & 42 & & \\
\hline
\end{tabular}

was $8.12 \pm 2.55$ and for perception was $32.47 \pm 3.62$.

On some statements, respondents had the positive perception (Table 3); they had been already aware that breast cancer may also happen to young women, however, $59.3 \%$ disagreed with this statement. They also recognized potential risk factors for breast cancer such as being female, alcohol consumption, polluted environment and radiation. A major proportion of respondents agreed that breastfeeding could protect women from getting breast cancer and they knew that any problem about breast was a serious condition. But they still perceived negatively toward other risk factors such as genetics, age at menarche, age at first live birth, estrogen exposure and geographic influence.

Using the Spearman correlation test, from all the characteristics of the students, the only family income had a significant correlation ( $p$ 0.012 ) with perception toward breast cancer risk (Table 4). The strength of correlation was weak $(\mathrm{r}=0.230)$.

There was a significant relationship between the level of knowledge and perception toward breast cancer risk $(\mathrm{p}<0.008)$, however, the strength of correlation was weak $(r=0.244)$ (Table 5).

\section{Discussions}

This study has explored the knowledge and perception about the risks of breast cancer among female senior high school students in Jatinangor, and the most of the female students had poor knowledge (69.5\%), similar to several other previous studies, that have shown inadequate knowledge about breast cancer. $^{7-15,17-19}$

Most female students (56.8\%) have positive perceptions toward the risks of breast cancer, but, the negative perception is also in a high percentage $(43.2 \%)$ and no significant difference between those with a positive perception. Many participants have already acknowledged the potential risk factors for breast cancer. Compared to the previous studies in Australia ${ }^{15}$ and Ohio $^{11}$ it shows that women perceive breast cancer to be a serious illness but they do not think that breast cancer is a threat to them and this disease is rather for older women. The students have very limited knowledge about breast cancer and they have never thought about their perception before this study. ${ }^{15}$

Interestingly, this study revealed that there was a relationship between knowledge and perception of the risks of breast cancer $(p<0.008)$. Most of the respondents with moderate knowledge had a positive perception of the risks of breast cancer. This is consistent with the theory of health belief model, stating that knowledge is a modifying factor that affects how someone perceived a disease. A higher level of knowledge means that they know the fact, therefore they perceived breast cancer positively. ${ }^{20}$

Furthermore, there is no relationship between the educational level of the respondents' mothers with the perception of the respondents on the risks of breast cancer. Ideally, when there is a barrier in the information of breast cancer, young women would prefer to obtain information from their mothers. ${ }^{15}$ Therefore, a mother's knowledge would affect their daughter's perception of breast cancer and it would be influenced by the educational level of the mother.$^{14}$ However, our study is unable to prove this because some students do not live with their mothers. Further analysis of this data would be interesting to explore.

Family income showed a significant relationship with respondents' perception of the risks of breast cancer. Respondents from higher family income would have a positive perception, ${ }^{7}$ and knowledge would affect their perception. ${ }^{20}$ However, no research available has been identified so far about the relationship of family income directly to perception of the risks of breast cancer. Furthermore, a family history of breast cancer might have a relationship with respondents' perception of 
the risks of breast cancer. Women who have a family history of breast cancer might have a significant impact on their perception of breast cancer compared to women without a family history of breast cancer that perceive they are not at risk of developing breast cancer. ${ }^{15}$ Women with a family history of breast cancer have higher knowledge in comparison to the opposite but with no significant difference. ${ }^{14}$ Other predictor is family size staying at the same house.

Limitation of this study among others is the family size that cannot be explored due to the type of schools; one school is attended by students coming from higher social and economic status than other schools and the other school is a boarding school of which the number of their family member living in the same house, maybe biased, therefore they have less time interacting with their family. Further study needs to stratify these factors. Furthermore, this study is unable to identify more about respondents' family history of breast cancer, both first degree (mother, sister, grandmother) and second-degree relatives, as well as their source of information about breast cancer.

To conclude, most of the female students of senior high school in Jatinangor have poor knowledge and negative perception toward the risks of breast cancer. Factors associated with perception are the level of knowledge and socioeconomic family background. Young women in high schools should be given a breast cancer education and counseling, therefore, their knowledge andaffect their perception about the risk factors contributing to breast cancer may increase, and they will be more concerned and aware of their health status.

\section{Acknowledgement}

We are grateful to the head of Public Senior High School (Sekolah Menengah Atas Negeri, SMAN) Jatinangor, Vocational School (Sekolah Menengah Kejuruan, SMK) Padjadjaran and Senior High School (Sekolah Menengah Atas, SMA) Al-Masoem for their permission for this study.

\section{References}

1. Ferlay J, Shin H-R, Bray F, Forman D, Mathers C, Parkin DM. Estimates of worldwide burden of cancer in 2008: GLOBOCAN 2008. Int J Cancer. 2010;127(12):2893-917.

2. Parkin DM, Bray F, Ferlay J, Pisani P. Global cancer statistics, 2002. CA Cancer J Clin.
2005;55(2):74-108.

3. Jemal A, Bray F, Center MM, Ferlay J, Ward E, Forman D. Global cancer statistics. CA Cancer J Clin. 2011;61(2):69-90.

4. Smith RA, Caleffi M, Albert US, Chen TH, Duffy SW, Franceschi D, et al. Breast cancer in limited-resource countries: early detection and access to care. Breast J. 2006;12(Suppl 1):S16-26.

5. Smith RA, Cokkinides V, Eyre HJ. American cancer society guidelines for the early detection of cancer, 2006. CA Cancer J Clin. 2006;56(1):11-25.

6. Cancer Australia Australian Government. Early detection of breast cancer. 2009 [cited 2013 March 3]: Available from: http://canceraustralia.gov.au/about-us/ position-statements/early-detectionbreast-cancer.

7. Hadi MA, Hassali MA, Shafie AA, Awaisu A. Knowledge and perception of breast cancer among women of various ethnic groups in the State of Penang: a cross-sectional survey. Med Princ Pract. 2010;19(1):61-7.

8. Hadi MA, Hassali MA, Shafie AA, Awaisu A. Evaluation of breast cancer awareness among female university students in Malaysia. Pharm Pract (Granada). 2010;8(1):29-34.

9. Oluwatosin OA. Rural women's perception of breast cancer and its early-detection measures in Ibadan, Nigeria. Cancer Nurs. 2006;29(6):461-6.

10. Montazeri A, Vahdaninia M, Harirchi I, Harirchi AM, Sajadian A, Khaleghi F, et al. Breast cancer in Iran: need for greater women awareness of warning signs and effective screening methods. Asia Pac Fam Med. 2008;7(1):6.

11. Rahman SM, Rahman S. Breast cancer perceptions, knowledge and behavioral practices among women living in a rural community. Int J Canc Prev. 2008;2(6):415-25.

12. Webster P, Austoker J. Women's knowledge about breast cancer risk and their views of the purpose and implications of breast screening-a questionnaire survey. J Public Health. 2006;28(3):197-202.

13. Mafuvadze B, Manguvo A, He J, Whitney SD, Hyder SM. Breast cancer knowledge and awareness among high school and college students in Mid-Western USA. Int J Sci Educ, Part B. 2014;3(2):144-58.

14. Al-Dubai SA, Qureshi AM, Saif-Ali R, Ganasegeran K, Alwan MR, Hadi JI. Awareness and knowledge of breast cancer and mammography among a group 
of Malaysian women in Shah Alam. Asian Pac J CancerPrev. 2011;12(10):2531-8.

15. Johnson NE. Young Women's Perception of Breast Cancer [Dissertation]. Bendigo: La Trobe University; 2006.

16. Lester SC. The breast. In: Kumar V, Abbas AK, Fausto N, Aster JC, editors. Robbins and cotran pathologic basis of disease. $8^{\text {th }}$ ed. Philadelphia: Saunders Elsevier; 2010. p. 1065-93.

17. Dandash KF, Al-mohaimeed A. Knowledge, attitudes, and practices surrounding breast cancer and screening in female teachers of Buraidh, Saudi Arabia. Int J Health Sci. 2007;1(1):61-71.

18. Okobia $\mathrm{MN}$, Bunker $\mathrm{CH}$, Okonofua FE,
Osime U. Knowledge, attitude and practice of Nigerian women towards breast cancer: a cross sectional study. World J Surg Onc. 2006;4:11.

19. Parsa P, Kandiah M, Rahman HA, Zulkefli MA. Knowledge and behavior regarding breast cancer screening among female teachers in Selangor, Malaysia. Asian Pacific J Cancer Prev. 2008; 9:221-8.

20. Champion VL, Skinner CS. The health belief model. In: Glanz K, Rimer BK, Viswanath $\mathrm{K}$, editors. Health behavior and health education: theory, research, and practice. $4^{\text {th }}$ ed. San Fransisco: John Wiley \& Sons; 2008. p. 45-50. 